\title{
Post-Annealing Effects on Properties of ZnO Nanorods Grown on Au Seed Layers
}

\author{
Min Young Cho, Min Su Kim, Hyun Young Choi, Kwang Gug Yim, and Jae-Young Leem* \\ Department of Nano Systems Engineering, Center for Nano Manufacturing, Inje University, Gimhae 621-749, Korea \\ EE-mail: jyleem@inje.ac.kr \\ Received November 25, 2010, Accepted January 6, 2011
}

\begin{abstract}
$\mathrm{ZnO}$ nanorods were grown by hydrothermal method. Two kinds of seed layers, $\mathrm{Au}$ film and island seed layers were prepared to investigate the effect of seed layer on $\mathrm{ZnO}$ nanorods. The $\mathrm{ZnO}$ nanorod on $\mathrm{Au}$ island seed layer has more unifom diameter and higher density compared to that of $\mathrm{ZnO}$ nanorod on $\mathrm{Au}$ film seed layer. The $\mathrm{ZnO}$ nanorods on $\mathrm{Au}$ island seed layer were annealed at various temperatures ranging from 300 to $850{ }^{\circ} \mathrm{C}$. The pinholes at the surface of the $\mathrm{ZnO}$ nanorods is formed as the annealing temperature is increased. It is noted that the pyramid structure on the surface of $\mathrm{ZnO}$ nanorod is observed at $850^{\circ} \mathrm{C}$. The intensity of $\mathrm{ZnO}(002)$ diffraction peak in X-ray diffraction pattern and intensity of near band edge emission (NBE) peak in photoluminescence (PL) are increased as the $\mathrm{ZnO}$ nanorods were annealed at the temperature of $300^{\circ} \mathrm{C}$.
\end{abstract}

Key Words : Zinc oxide, Nanorod, Pyramid, Au seed layer, Hydrothermal method

\section{Introduction}

$\mathrm{ZnO}$ is an n-type semiconductor with a hexagonal wurtzite structure and a large exciton binding energy of $60 \mathrm{meV}$, which is 2.4 times that of $\mathrm{GaN}^{1}{ }^{1} \mathrm{ZnO}$ has been studied extensively for its potential use in various applications, such as gas sensors, ${ }^{2}$ solar cells, ${ }^{3}$ photo-detectors, ${ }^{4}$ and light emitting diodes. ${ }^{5}$ Especially $\mathrm{ZnO}$ nanorods also have the advantages of large surface area, radiation hardness, ${ }^{6}$ thermal and mechanical stability. ${ }^{7}$ The physical properties of the nano- $\mathrm{ZnO}$ materials depend on the microstructure including morphology, crystal size, orientation, aspect ration and crystalline density. ${ }^{8}$ For many of these applications, it is important to investigate the device characteristics using small size and long and highly oriented nanorods, and to see if the length control can improve the device performance and design. To date, various synthetic approaches have been developed to fabricate $\mathrm{ZnO}$ nanorod arrays such as thermal evaporation, ${ }^{9}$ metal-organic chemical vapor deposition (MOCVD) ${ }^{10}$ chemical or physical vapor deposition, ${ }^{11}$ hydrothermal method, ${ }^{12}$ etc. The hydrothermal method showed some advantages compared with others, such as use of simple equipment, low-temperature deposition, low cost, less hazardous. The growth condition such as morphology of a zinc metal seed layer, $\mathrm{pH}$, growth temperature, and concentration of zinc salt in aqueous solution determine growth characteristics of $\mathrm{ZnO}$ nanostructures. ${ }^{13,14}$ It is important to study their growth parameters to control growth of $\mathrm{ZnO}$ nanostructures. Especialy, the seed material is important for the growth of high-quality $\mathrm{ZnO}$ nanostructures. Nevertheless, it is not well understood how the seed layer affects the growth of $\mathrm{ZnO}$ nanostructures.

In this study, two types of seed layers, Au film seed layer and $\mathrm{Au}$ island seed layer, were prepared. The $\mathrm{ZnO}$ nanorods were grown on $\mathrm{Au}$ seed layers by hydrothermal method and the $\mathrm{ZnO}$ nanorods grown on $\mathrm{Au}$ island seed layer were annealed at various temperatures ranging from 300 to 850 ${ }^{\circ} \mathrm{C}$. Field emission scanning electron microscopy (FE-SEM), $\mathrm{X}$-ray diffraction (XRD), and photoluminescence (PL) were employed to investigate the structural and optical properties of the $\mathrm{ZnO}$ nanorods.

\section{Experimental}

$\mathrm{ZnO}$ nanorods were grown on p-type $\mathrm{Si}(100)$ substrates by hydrothermal method. The Si substrates were cleaned in a piranha solution $\left(\mathrm{H}_{2} \mathrm{SO}_{4}: \mathrm{H}_{2} \mathrm{O}_{2}=8: 1\right)$ at $110{ }^{\circ} \mathrm{C}$ for $15 \mathrm{~min}$ and then hydrofluoric acid (HF $50 \%: \mathrm{H}_{2} \mathrm{O}=1: 9$ ) for $5 \mathrm{~min}$. Two kinds of seed layers which are Au film and Au island seed layer were used. The $5 \mathrm{~nm}$ of Au film seed layer was deposited by ion-sputter. The Au island seed layer was prepared by annealing process of the Au film at the temperature of $1000{ }^{\circ} \mathrm{C} . \mathrm{ZnO}$ nanorods on the Au seed layers were grown by hydrothermal method. The aqueous solution of zinc nitrate hexahydrate $\left[\mathrm{Zn}\left(\mathrm{NO}_{3}\right)_{2} \cdot 6 \mathrm{H}_{2} \mathrm{O}\right]$ and hexamethylenetetramine (HMT) $\left[\mathrm{C}_{6} \mathrm{H}_{12} \mathrm{~N}_{4}\right]$ were prepared for hydrothermal growth and mixed together. The concentrations of both were fixed at $0.3 \mathrm{M}$. The aqueous solution was stirred and then transferred into a Teflon-lined stainless steel autoclave. Then the substrate was immersed into the aqueous solution. The growth temperature was kept at $130{ }^{\circ} \mathrm{C}$ for $7 \mathrm{~h}$. Subsequently, the autoclave was cooled down naturally. the substrate were thoroughly rinsed with de-ionized water and blown dry with nitrogen gas $(6 \mathrm{~N})$. The $\mathrm{ZnO}$ nanorods were annealed using thermal annealing system at 300,500 , and $850{ }^{\circ} \mathrm{C}$ for 5 min under argon atmosphere.

\section{Results and Discussion}

Figure 1 shows the AFM $1 \times 1 \mu \mathrm{m}$ images of the surface of (a) Au film seed layer and (b) Au island seed layer. The root-mean-square (RMS) roughness of the $\mathrm{Au}$ film and 

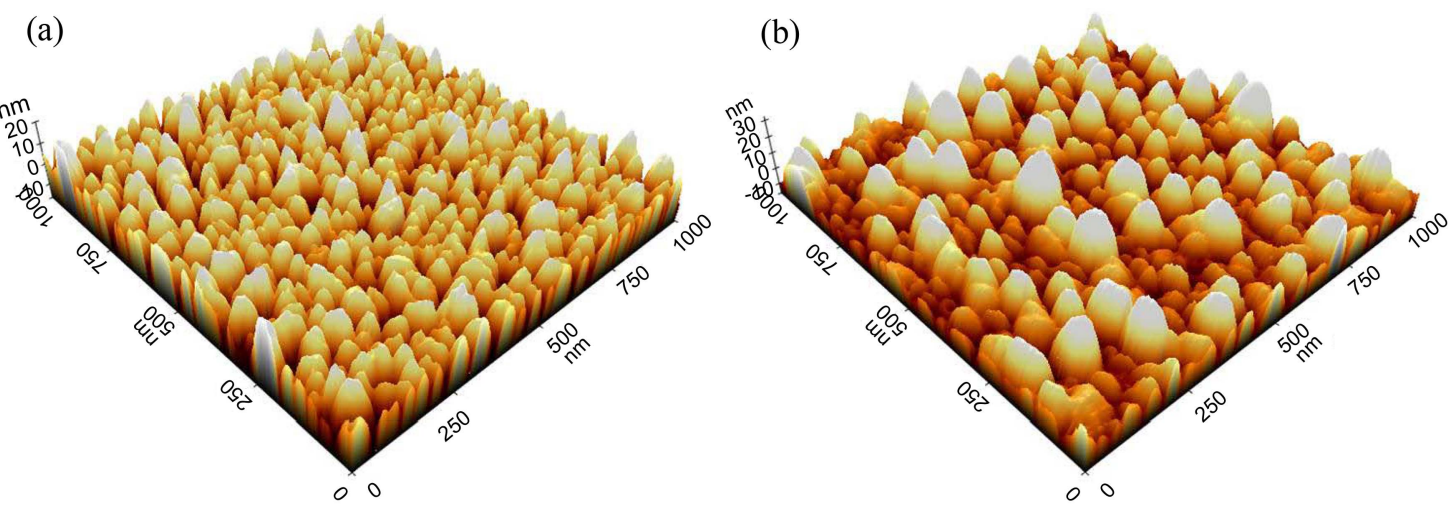

Figure 1. AFM images of (a) Au film and (b) Au island seed layer.

island are 5.15 and $7.69 \mathrm{~nm}$, respectively. The Au film seed layer exhibits dense and uniform morphology. After the annealing process, the surface morphology of the Au seed layer changes from film to island. There are two possible reasons to demonstrate the changes in surface morphology of the Au seed layers. One is that the $\mathrm{Au}$ is pulled together from the nearest surface to form the island after the annealing because gold has a rather high surface tension. Other is formation of the Au-Si alloy ball on the Si substrate surface because Au nanoparticle reacted with the Si substrate. ${ }^{15}$ In general, the melting point of $\mathrm{Au}$ is $1064{ }^{\circ} \mathrm{C}$, however, when a metal forms an alloy with $\mathrm{Si}$ at a certain atomic percentage, the melting temperature, called eutectic temperature, of the alloy can be much lower than that of both the metal and $\mathrm{Si}$. The eutectic temperature for Au-Si alloys is $360{ }^{\circ} \mathrm{C} .{ }^{16} \mathrm{In}$ our case, the temperature of the $1000{ }^{\circ} \mathrm{C}$ is much higher than the eutectic temperature, so, Au-Si alloys were formed at the interface between the Si substrate and the $\mathrm{Au}$ film and then the Au film were gradually melted to $\mathrm{Au}$ isalnd.

Figure 2 shows the SEM images of the $\mathrm{ZnO}$ nanorods on $\mathrm{Au}$ film seed layer and $\mathrm{Au}$ island seed layer. In the
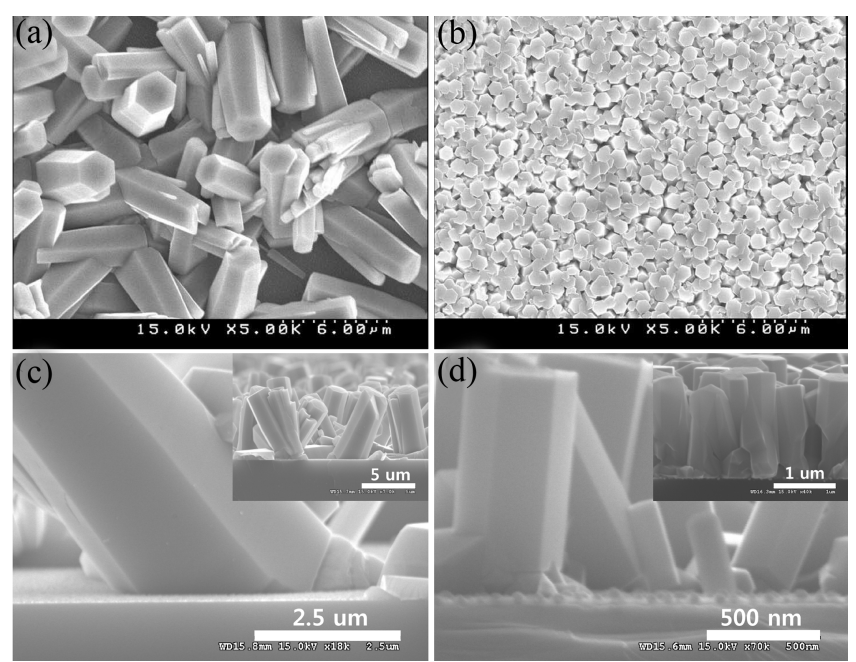

Figure 2. Top view SEM images of $\mathrm{ZnO}$ nanorods on (a) Au film and (b) Au island seed layer and cross section SEM images of $\mathrm{ZnO}$ nanorods on (c) Au film and (d) Au island seed layer. growth process, $\mathrm{Zn}^{2+}$ and $\mathrm{OH}$ are provided by hydration of $\mathrm{Zn}\left(\mathrm{NO}_{3}\right)_{2}$ and HMT. The following reactions are privotal in the formation of $\mathrm{ZnO}$ :

$$
\begin{gathered}
\left(\mathrm{CH}_{2}\right)_{6} \mathrm{~N}_{4}+\mathrm{H}_{2} \mathrm{O} \rightarrow 4 \mathrm{NH}_{3(\mathrm{~g})}+6 \mathrm{HCHO}_{(\mathrm{g})} \\
\mathrm{NH}_{3}+\mathrm{H}_{2} \mathrm{O} \rightarrow \mathrm{NH}_{4}^{+}+\mathrm{OH}^{-}
\end{gathered}
$$

Here, $\mathrm{Zn}^{2+}$ are known to react readily with $\mathrm{OH}$ to form more soluble $\mathrm{Zn}(\mathrm{OH})_{2}$ complexes, which act as the growth unit of $\mathrm{ZnO}$ nanostructures. Finally, $\mathrm{ZnO}$ is obtained by decomposition of $\mathrm{Zn}(\mathrm{OH})_{2}$. Therefore, the key chemical reactions involved in hydrothermal synthesis can be formulated as follows:

$$
\begin{gathered}
\mathrm{Zn}^{2+}+2 \mathrm{OH}^{-} \leftrightarrow \mathrm{Zn}(\mathrm{OH})_{2(\mathrm{~s})} \\
\mathrm{Zn}(\mathrm{OH})_{2} \leftrightarrow \mathrm{ZnO}_{(\mathrm{s})}+\mathrm{H}_{2} \mathrm{O}
\end{gathered}
$$

When the concentration of $\mathrm{Zn}^{2+}$ and $\mathrm{OH}^{-}$exceed supersaturation, $\mathrm{ZnO}$ nuclei are formed on the substrate surface. With increasing temperature, these complexes become dehydrated and heterogeneous nucleation of $\mathrm{ZnO}$ crystals takes place at the interface between substrate and solution. In the initial growth stage of the $\mathrm{ZnO}$ nanorods, the $\mathrm{Au}$ film and island, which was deposited onto a Si wafer, mainly act like nucleation sites. The SEM images show that the morphology and size of $\mathrm{ZnO}$ nanorods is obviously different. When the $\mathrm{Au}$ island seed layers are introduced, the dense-arrayed, regular oriented $\mathrm{ZnO}$ nanorods can be obtained as shown in Figure 2(a) and (b). As shown in top view of $\mathrm{ZnO}$ nanorods, the diameter of $\mathrm{ZnO}$ nanorods on $\mathrm{Au}$ film is much bigger than that of $\mathrm{ZnO}$ nanorods on $\mathrm{Au}$ island. The length of $\mathrm{ZnO}$ nanorods on $\mathrm{Au}$ film is also much higher than that of $\mathrm{ZnO}$ nanorods on $\mathrm{Au}$ island as shown in the cross section SEM images. The roughness and thickness of the seed layers affect the $\mathrm{ZnO}$ nanorods. In general, the seed layers with more rough surface and higher length can provide conditions to form nuclei easily. For the $\mathrm{ZnO}$ nanorods grown on $\mathrm{Au}$ island, the nuclei were formed with higher density due to rougher surface of the Au island seed layer compared to that of the Au film seed layer. So, the density and uniformity of the $\mathrm{ZnO}$ nanorods is improved. On the other hand, the density and uniformity is inversely proportional to length. The similar results were reported by 


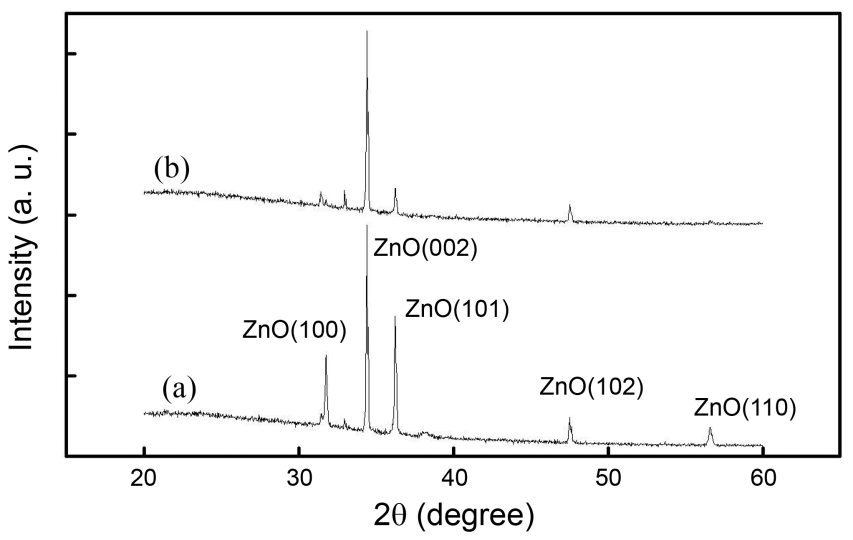

Figure 3. XRD patterns of $\mathrm{ZnO}$ nanorods on (a) Au film and (b) $\mathrm{Au}$ island seed layer.

\section{Lee et $a l .{ }^{17}$}

Figure 3 shows the XRD spectra of the $\mathrm{ZnO}$ nanorods. All the $\mathrm{ZnO}$ nanorods exhibit a diffraction peak around $34^{\circ}$, which is the $\mathrm{ZnO}$ (002). The tiny $\mathrm{ZnO}$ (100), (101), (102), and (110) orientation XRD peak is also observed, indicating that small amounts of other domain structures exist in $\mathrm{ZnO}$ nanorods. To describe the preferred orientation, the texture coefficient (TC) was used. The $T C$ represents the texture of the particular plane, deviation of which from unity implies the preferred growth. The $T C$ has been calculated from XRD data, using the following expression ${ }^{18}$ :

$$
T C_{(h k l)}=\frac{I_{(h k l)} / I_{0(h k l)}}{\frac{1}{n} \sum_{i=1}^{n}\left(I_{(h k l)} / I_{0(h k l)}\right)}
$$

Where $T C_{(h k l)}$ is the texture coefficient for the reflection $(h k l), I_{(h k l)}$ is the relative diffraction intensity of $(h k l)$ diffraction peak from experimental data, and $I_{0(h k l)}$ is the standard peak intensity for the reflection $(h k l)$ according to JCPDS reference file. Since the data on JCPDS card are measured from pure single-phase powder samples, the effects of preferred orientation, solid solution and other impurities disturbance can be neglected. That is to say, the sample of JCPDS is in a random state. For randomly oriented crystals, $T C_{0(h k l)}$ $=1$ because $I_{h k l}=I_{0(h k l)}$. As $T C_{(h k l)}$ approach to 1 , the less likely the $(h k l)$ crystal planes possess preferred orientation. Deviation from 1 implies preferred orientation is likely. High $T C_{(h k l)}$ value means reflections than in a material with a random microstructure. Table 1 shows the calculated TC for $\mathrm{ZnO}$ nanorods on $\mathrm{Au}$ films seed layer and $\mathrm{Au}$ island seed layer. Both $\mathrm{ZnO}$ nanorods grown on $\mathrm{Au}$ film seed layer and

Table 1. The texture coefficients of the different planes for the $\mathrm{ZnO}$ nanorods grown on Au films seed layer and Au island seed layer

\begin{tabular}{lccccc}
\hline \multirow{2}{*}{ Seed layer } & \multicolumn{5}{c}{ Texture coefficient (TC) } \\
\cline { 2 - 6 } & $(100)$ & $(002)$ & $(101)$ & $(102)$ & $(110)$ \\
\hline Au film & 0.75 & 2.66 & 0.70 & 0.56 & 0.34 \\
Au island & 0.17 & 3.09 & 0.20 & 0.53 & - \\
\hline
\end{tabular}

Au island seed layer have high $T C_{(002)}$ value. The high value of $T C_{(002)}$ indicates the maximum preferred orientation of the films along the (002). $\mathrm{ZnO}$ are well known to be usually grown with a c-axis preferred orientation because of the low surface energy of the basal plane in $\mathrm{ZnO}$, leading to a preferred growth in the (002) direction. ${ }^{19}$ As seed layer changed from $\mathrm{Au}$ film to $\mathrm{Au}$ island, $T C_{(002)}$ is increased while other $T C$ value which are $T C_{(100)}, T C_{(101)}, T C_{(102)}$, $T C_{(110)}$ are decreased. The annealed seed layers help form well-aligned $\mathrm{ZnO}$ nanorods in the hydrothermal process as nanorods are grown along the normal orientation of the $\mathrm{ZnO}$ thin films. It is also shown in SEM images in Figure 2, the $\mathrm{ZnO}$ nanorods on $\mathrm{Au}$ film seed layers were grown randomly, while the $\mathrm{ZnO}$ nanorods on $\mathrm{Au}$ island seed layers were well aligned.

The $\mathrm{ZnO}$ nanorod grown on the $\mathrm{Au}$ seed layers were annealed at the temperature of 300,500 , and $850{ }^{\circ} \mathrm{C}$ to investigate the post-annealing effects on properties of the $\mathrm{ZnO}$ nanorod and its morphology as shown in Figure 4. The surface of the $\mathrm{ZnO}$ nanorod annealed at $300{ }^{\circ} \mathrm{C}$ is almost same compared to that of the as-grown $\mathrm{ZnO}$ nanorod. However, the pinholes have been observed to appear on the surface of $\mathrm{ZnO}$ nanorods after annealing at above $500{ }^{\circ} \mathrm{C}$ as shown in Figure 4(c) and (d). The formation of the pinholes on the $\mathrm{ZnO}$ nanorods as functions of the annealing temperature was studied in our previous study. ${ }^{20}$ In the previous work, two possible reasons for the formation of pores were discussed. One is desorption of zinc and oxygen at the defect sites and the other is decomposition of volatile gas and unreacted material. The release of volatile gas and surface reconstruction or evaporation of unreacted material such as zinc nitride during the annealing process is also discussed in the other studies. ${ }^{21,22}$ The surface of $\mathrm{ZnO}$ nanorods grown by hydrothermal method was prone to absorb various kinds of functional groups. According to the chemical reaction in the solution, these functional groups
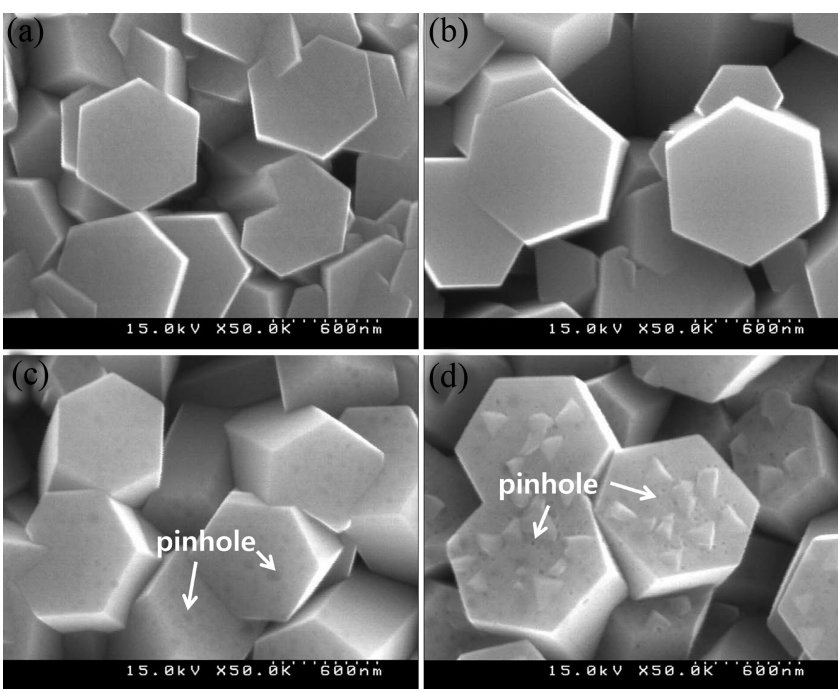

Figure 4. SEM images of (a) as-grown $\mathrm{ZnO}$ nanorod on $\mathrm{Au}$ island seed layer and $\mathrm{ZnO}$ nanorods on $\mathrm{Au}$ island seed layer annealed at (b) $300{ }^{\circ} \mathrm{C}$, (c) $500{ }^{\circ} \mathrm{C}$, and (d) $850{ }^{\circ} \mathrm{C}$. 


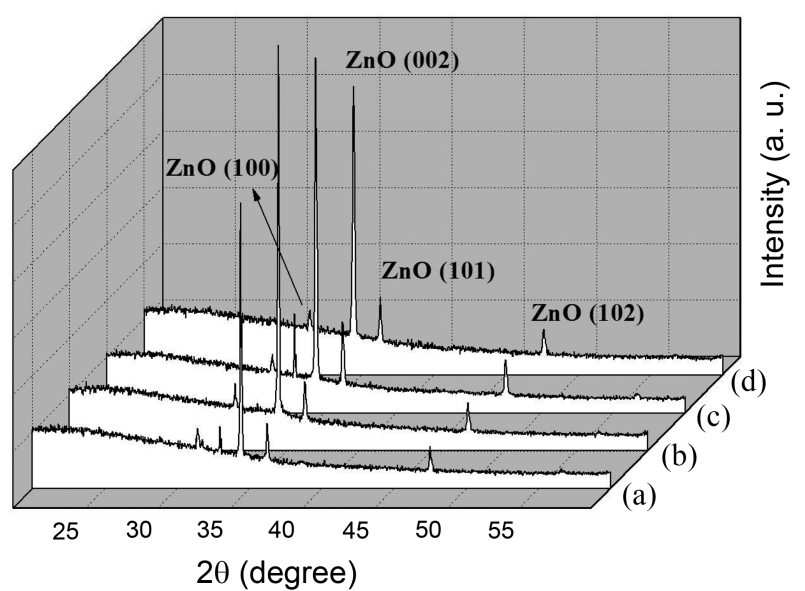

Figure 5. $\mathrm{XRD}$ spectra of (a) as-grown $\mathrm{ZnO}$ nanorod on $\mathrm{Au}$ island seed layer and $\mathrm{ZnO}$ nanorods on $\mathrm{Au}$ island seed layer annealed at (b) $300{ }^{\circ} \mathrm{C}$, (c) $500{ }^{\circ} \mathrm{C}$, and (d) $850{ }^{\circ} \mathrm{C}$.

should be related to the elements such as carbon, nitrogen, and hydrogen. Note that the $\mathrm{ZnO}$ nanopyramid is formed on the surface of the $\mathrm{ZnO}$ nanorods annealed at $850{ }^{\circ} \mathrm{C}$. It is assumed that reaction between the residual, functional group, and unreacted material occurs at the relatively high annealing temperature which leads to form the $\mathrm{ZnO}$ nanopyramid. It is noted that, in the previous works, the $\mathrm{ZnO}$ nanopyramid was not observed. The reason of this is that more volatile gas was released and unreacted materials are evaporated as the annealing temperature is increased up to $850{ }^{\circ} \mathrm{C}$. Thus the possibility to form $\mathrm{ZnO}$ nanostructure by evaporated material is increased. However, the detail mechanisms are not fully understood yet. Further studies are needed to demonstrate it.

Figure 5 shows the XRD spectra of the post-annealed $\mathrm{ZnO}$ nanorods at the various temperatures. The entire $\mathrm{ZnO}$ nanorods exhibit $\mathrm{ZnO}$ (002), (100), (101), (102). Table 2 shows the calculated $T C$ for $\mathrm{ZnO}$ nanorods with various annealing temperature. $T C_{(002)}$ is increased as the $\mathrm{ZnO}$ nanorods in annealed at $300{ }^{\circ} \mathrm{C}$, while $T C_{(100)}, T C_{(101)}$, and $T C_{(102)}$ are decreased. It is assumed that surface reconstruction and evaporation of unreacted material reduce the $T C_{(100)}, T C_{(101)}$, and $T C_{(102)}$. As the annealing temperature further increased, $T C_{(002)}$ decreased again, while $T C_{(101)}$ and $T C_{(102)}$ increased. It is assumed that the structural defects such as the pinholes appearing after annealing above $500{ }^{\circ} \mathrm{C}$ which is result of a degassing process.

Table 2. The texture coefficients of the different planes for the $\mathrm{ZnO}$ nanorods annealed at various temperature

\begin{tabular}{ccccc}
\hline \multirow{2}{*}{$\begin{array}{c}\text { Annealing } \\
\text { temperature }\left({ }^{\circ} \mathrm{C}\right)\end{array}$} & \multicolumn{4}{c}{ Texture coefficient (TC) } \\
\cline { 2 - 5 } & $(100)$ & $(002)$ & $(101)$ & $(102)$ \\
\hline As-grown & 0.17 & 3.09 & 0.20 & 0.53 \\
300 & 0.14 & 3.24 & 0.14 & 0.47 \\
500 & 0.06 & 3.04 & 0.27 & 0.63 \\
850 & 0.09 & 3.10 & 0.24 & 0.58 \\
\hline
\end{tabular}

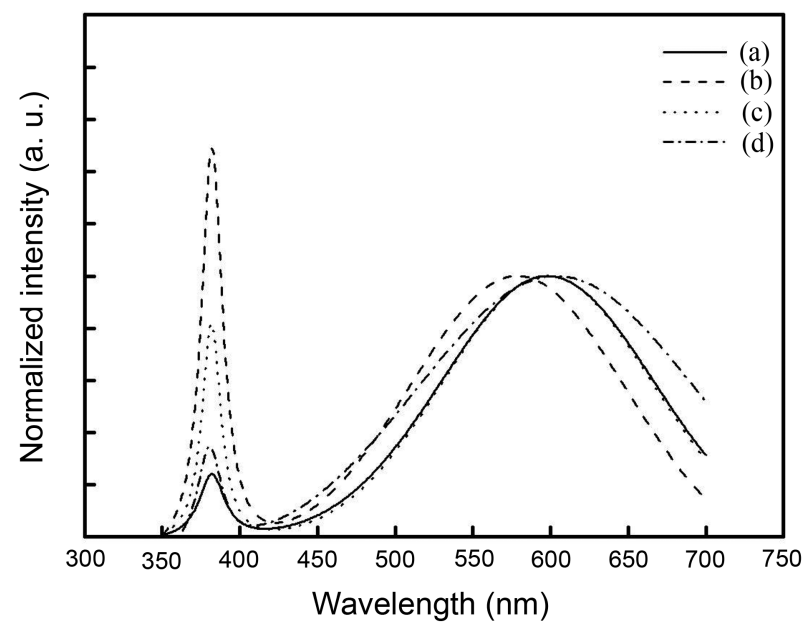

Figure 6. PL spectra of (a) as-grown $\mathrm{ZnO}$ nanorod on $\mathrm{Au}$ island seed layer and $\mathrm{ZnO}$ nanorods on $\mathrm{Au}$ island seed layer annealed at (b) $300^{\circ} \mathrm{C}$, (c) $500{ }^{\circ} \mathrm{C}$, and (d) $850^{\circ} \mathrm{C}$.

In order to investigate the optical properties of the $\mathrm{ZnO}$ nanorods, we carried out PL measurement at room temperature by using a $\mathrm{He}-\mathrm{Cd}$ laser with an excitation power of 30 $\mathrm{mW}$ and a 1-m single-grating monochromator with a photomultiplier tube. The PL spectra of the post-annealed $\mathrm{ZnO}$ nanorods at the various temperatures are shown in Figure 6. The PL spectra show a sharp near-band-edge (NBE) emission, which is generated by the free-exciton recombination at 380 $\mathrm{nm}$. A broad deep-level emission (DLE), which is caused by impurities and structural defects, as observed from $578 \mathrm{~nm}$ (yellow emission) to 598 (orange emission). The yellow emission which are common in hydrothermally grown $\mathrm{ZnO}$ can be attributed to defects of $\mathrm{O}_{\mathrm{i}}$ and the presence of $\mathrm{Zn}(\mathrm{OH})_{2}$ on the surface..$^{23}$ The yellow-orange emission in $\mathrm{ZnO}$ has been also attributed to $\mathrm{O}_{\mathrm{i}}{ }^{24} \mathrm{After}$ the $\mathrm{ZnO}$ nanorod annealed at $300{ }^{\circ} \mathrm{C}$, a remarkable strong enhancement in $\mathrm{PL}$ intensity ratio appeared by almost a factor of 7 compared to the as-grown $\mathrm{ZnO}$ nanorod. However, after the $\mathrm{ZnO}$ nanorods were annealed under 500 and $850^{\circ} \mathrm{C}$, the NBE intensity apparently decreased step by step again in comparison with the PL spectrum of the $\mathrm{ZnO}$ nanorod annealed at $300{ }^{\circ} \mathrm{C}$. The enhancement obtained for PL intensity ratio after annealing at $300{ }^{\circ} \mathrm{C}$ is probably related to desorption of hydroxyl groups, since the desorption rate of the hydroxyl groups peaks at $\sim 150{ }^{\circ} \mathrm{C}$, while hydrogen predominantly desorbs at $\sim 420{ }^{\circ} \mathrm{C}^{25}$ Since hydrogen can passivate the defects and consequently enhance the NBE to DLE ratio, ${ }^{25}$ the worsening of the NBE to DLE ratio for further annealing temperature is likely related to the release of residual hydrogen.

\section{Conclusion}

The surface morphology of the Au seed layer changes from film to island after the annealing process. The $\mathrm{ZnO}$ nanorod on $\mathrm{Au}$ island has higher density and uniform diameter compared to the $\mathrm{ZnO}$ nanorod on $\mathrm{Au}$ film. The pin- 
holes were formed by annealing process with the temperature up to $700{ }^{\circ} \mathrm{C}$. The $\mathrm{ZnO}$ nanopyramid was grown on the surface of the $\mathrm{ZnO}$ nanorod annealed at the temperature of $850{ }^{\circ} \mathrm{C}$. The value of $T C_{(002)}$ is increased as $\mathrm{ZnO}$ nanorods annealed at $300{ }^{\circ} \mathrm{C}$. The luminescent efficiency of NBE peak is also improved at $\mathrm{ZnO}$ nanorods annealed at $300{ }^{\circ} \mathrm{C}$. It is suggested that the uniformity of the $\mathrm{ZnO}$ nanorods can be improved by annealing of $\mathrm{Au}$ seed layer. And also, the temperature of $300{ }^{\circ} \mathrm{C}$ is suitable to obtain the highly (002)oriented $\mathrm{ZnO}$ nanorods with good luminescence performance.

Acknowledgments. This research was supported by Basic Science Research Program Through the National Research Foundation of Korea (NRF) funded by the Ministry of Education, Science and Technology (No. 2010-0016147).

\section{References}

1. Zhang, Y.; Du, G.; Liu, D.; Wang, X.; Ma, Y.; Wang, J.; Yin, J.; Yang, X.; Hou, X.; Yang, S. J. Crystal Growth 2002, 243, 439.

2. Golego, N.; Studenikin. S. A.; Cocivera, M. J. Electochem. Soc. 2000, $147,1592$.

3. Rau, U.; Schmidt, M. Thin Solid Films 2001, 387, 141.

4. Liu, Y.; Gorla, C. R.; Liang, S. J. Electron. Mater. 2000, 29, 60.

5. Soki, T.; Hatanaka, Y.; Look, D. C. Appl. Phys. Lett. 2000, 76, 3257.

6. Kong, Y. C.; Yu, D. P.; Zhang, B.; Fang, W.; Feng, S. Q. Appl. Phys. Lett. 2001, 78, 407.

7. Maejima, K.; Ueda, M.; Fujita, S. Z.; Fujita, S. G. Jpn. J. Appl. Phys. 2003, 42, 2600.

8. Wang, Z. L.; Kong, X. Y.; Ding, Y.; Gao, P.; Hughes, W. L.; Yang,
R. Adv. Funct. Mater. 2004, 14, 943.

9. Li, Y.; Ding, Y.; Wang, Z. Adv. Mater. 1999, 11, 844.

10. Look, D. C. Mater. Sci. Eng. B 2001, 80, 383.

11. Ozgur, U.; Alivov, Y. I.; Liu, C.; Teke, A.; Reshchikov, M. A.; Dogan, S.; Avrutin, V.; Cho, S. J.; Morkoc, H. A. J. Appl. Phys. 2005, 98, 041301

12. Tian, Z. R.; Voigt, J. A.; Liu, J.; Mckenzie, B.; Mcdermott, M. J.; Rodriguez, M. A.; Konishi, H.; Xu, H. Nat. Mater. 2003, 2, 821.

13. Baruah, S.; Dutta, J. Sci. Technol. Adv. Mater. 2009, 10, 013001.

14. Lee, Y.; Zhange, Y.; Ng, S. L. G.; Kartawidjaja, F. C.; Wang, J. J. Am. Ceram. Soc. 2009, 92, 1940.

15. Sun, S. H.; Meng, G. W.; Zhang, M. G.; Hao, Y. F.; Zhang, X. R.; Zhang, L. D. J. Phys. Chem. B 2003, 107, 13029.

16. Massalski, T. B. Binary Alloy Phase Diagrams; OH: ASM International: 1990; $\mathrm{p} 428$

17. Lee, Y.-J; Sounart, T. L.; Scrymgeour, D. A.; Voigt, J. A.; Hsu, J. W. P. J. Cryst. Growth 2007, 304, 80 .

18. Romero, R.; Leinen, D.; Dalchiele, E. A.; Ramos-Barrado, J. R.; Martin, F. Thin Solid Films 2006, 515, 1942.

19. Kim, S. S.; Lee, B. T. Thin Solid Films 2004, 446, 307.

20. Jeon, S. M.; Kim, M. S.; Cho, M. Y.; Choi, H. Y.; Yim, K. G.; Kim, G. S.; Kim, H. G.; Leem, Lee, D.-Y.; Kim, J. S.; Kim, J. S.; Lee, J. I.; J.-Y. J. Korean Phys. Soc. 2010, 57, 1477.

21. Lee, S. H.; Lee, H. J.; Goto, H.; Cho, M. W.; Yao, T. Phy. Stat. Sol. (c) $\mathbf{2 0 0 7}, 4,1747$.

22. Wang, X.; Tian, Z.; Yu, T.; Tian, H.; Zhang, J.; Yuan, S.; Zhang, X.; Li, Z.; Zou, Z. Nanotech. 2010, 21, 065703.

23. Zhou, H.; Alves, H.; Hofmann, D. M.; Kriegseis, W.; Meyer, B. K.; Kaczmarczyk, G.; Hoffmann, A. Appl. Phys. Lett. 2002, 80, 210.

24. Kreye, M.; Postels, B.; Wehmann, H.-H.; Fuhrmann, D.; Hangleiter, A.; Waag, A. Phys. Stat. Sol. (c) 2006, 3, 992.

25. Xie, R.; Sekiguchi, T.; Ishigaki, T.; Ohashi, N.; Li, D.; Yang, D.; Liu, B.; Bando, Y. Appl. Phys. Lett. 2006, 88, 134103. 